\title{
Ventral Pallidal Projections to Mediodorsal Thalamus and Ventral Tegmental Area Play Distinct Roles in Outcome- Specific Pavlovian-Instrumental Transfer
}

\author{
Beatrice K. Leung and Bernard W. Balleine \\ Brain and Mind Research Institute, University of Sydney, Sydney, NSW 2050, Australia
}

Outcome-specific Pavlovian-instrumental transfer (PIT) demonstrates the way that reward-related cues influence choice between instrumental actions. The nucleus accumbens shell (NAc-S) contributes critically to this effect, particularly through its output to the rostral medial ventral pallidum (VP-m). Using rats, we investigated in two experiments the role in the PIT effect of the two major outputs of this VP-m region innervated by the NAc-S, the mediodorsal thalamus (MD) and the ventral tegmental area (VTA). First, two retrograde tracers were injected into the MD and VTA to compare the neuronal activity of the two populations of projection neurons in the VP-m during PIT relative to controls. Second, the functional role of the connection between the VP-m and the MD or VTA was assessed using asymmetrical pharmacological manipulations before a PIT test. It was found that, whereas neurons in the VP-m projecting to the MD showed significantly more neuronal activation during PIT than those projecting to the VTA, neuronal activation of these latter neurons correlated with the size of the PIT effect. Disconnection of the two pathways during PIT also revealed different deficits in performance: disrupting the VP-m to MD pathway removed the response biasing effects of reward-related cues, whereas disrupting the VP-m to VTA pathway preserved the response bias but altered the overall rate of responding. The current results therefore suggest that the VP-m exerts distinct effects on the VTA and MD and that these latter structures mediate the motivational and cognitive components of specific PIT, respectively.

Key words: basal ganglia; choice; decision-making; goal-directed action; rat

\section{Introduction}

The influence of cognitive functions such as predictive learning on choice between goal-directed actions is typically studied using the outcome-specific Pavlovian instrumental transfer (PIT) paradigm. In this paradigm, a Pavlovian conditioned stimulus (CS) predicting a particular outcome can be observed to bias choice toward actions associated with that predicted outcome relative to other actions (Colwill and Rescorla, 1988; Dickinson and Balleine, 2002). This PIT effect likely involves the interaction of several different psychological processes, but two kinds of process in particular: (1) the interaction of the learning processes engaged in encoding specific Pavlovian and instrumental contingencies and (2) the motivational processes that influence the effect of the Pavlovian contingency on the rate of instrumental performance.

At a neural level, although the specific PIT effect is known to rely on the nucleus accumbens shell (NAc-S) (Corbit and Bal-

Received Nov. 25, 2014; revised Feb. 1, 2015; accepted Feb. $17,2015$.

Author contributions: B.K.L. and B.W.B. designed research; B.K.L. performed research; B.K.L. and B.W.B. analyzed data; B.K.L. and B.W.B. wrote the paper.

This research was supported by the Australian Research Council (Laureate Fellowship FL0992409 to B.W.B.) and by the National Health and Medical Research Council of Australia (Grant 633267 to B.W.B.).

The authors declare no competing financial interests.

Correspondence should be addressed to Professor Bernard W. Balleine, Brain and Mind Research Institute, University of Sydney, 100 Mallett St, Camperdown, Sydney, NSW 2050, Australia. E-mail: bernard.balleine@sydney.edu.au.

DOI:10.1523/JNEUROSCI.4837-14.2015

Copyright (C) 2015 the authors $\quad 0270-6474 / 15 / 354953-12 \$ 15.00 / 0$ leine, 2011; Laurent et al., 2012; Laurent et al., 2014) and its projection to the rostral medial ventral pallidum (VP-m) (Leung and Balleine, 2013), how this information is used to control and coordinate the multiple processes involved in the performance of PIT remains unknown. The VP has been proposed to function as both an intrinsic component and an output relay of the basal ganglia and the region of the VP innervated by the NAc-S, the ventromedial VP (VPvm), maintains both a direct and an indirect output pathway via its projections to the mediodorsal thalamus (MD) and ventral tegmental area (VTA) (Zahm and Heimer, 1990; Heimer et al., 1991; Smith et al., 2013), allowing projection neurons from this structure to exert both an excitatory and an inhibitory effect on performance. Both the VTA and MD have been heavily implicated in reward-related actions, particularly with respect to their connections with the VP (McAlonan et al., 1993; Kalivas et al., 1999; Corbit et al., 2003; Geisler et al., 2008; Mahler and Aston-Jones, 2012; Mahler et al., 2014; Parnaudeau et al., 2015). More importantly, both the MD and VTA have been implicated in specific PIT but in different ways; whereas damage to the MD abolishes the effects of predictive learning on choice (Corbit et al., 2003; Ostlund and Balleine, 2008), inactivation of the VTA appears to attenuate the motivational impact of Pavlovian stimuli on response vigor while preserving their effect of on choice (Corbit et al., 2007).

The current experiments aimed to compare directly the importance of the connections between the VP-m and MD and the 
VP-m and VTA in the performance of specific PIT. First, we investigated the activity of populations of neurons in the VP-m that project to the VTA and/or to the MD during specific PIT compared with controls and, second, the functional importance of each of these connections was examined using a disconnection procedure with asymmetrical inactivation of the VP-m and the MD or VTA before a test of specific PIT. Finally, c-Fos expression in the MD and VTA was assessed during PIT after VP-m inactivation to assess regional changes in circuit-related activity driven by VP-m projection neurons mediating the specific PIT effect.

\section{Materials and Methods}

Overview of experiments

Two experiments were conducted to assess the role of the connection between the VP-m and MD and the VP-m and VTA during specific PIT. Experiment 1 aimed to investigate the neuronal activity during specific PIT of neurons in the VP-m projecting to the MD or the VTA using the neuronal activity marker c-Fos combined with retrograde tracers, Cholera toxin-b subunit (CTb, catalog \#104; List Biological Laboratories) and Fluoro-gold (FG; Fluorochrome), injected into the MD and VTA, respectively. Neuronal activity in these animals was compared with those that were either only exposed to the levers or those that were only exposed to the CS presentations. In Experiment 2, the VP-m/MD and VP-m/VTA connections were pharmacologically disconnected with a unilateral lesion to the MD or VTA and an infusion of the $\mathrm{GABA}_{\mathrm{A}}$ agonist muscimol into the VP-m in the ipsilateral or contralateral hemisphere before a specific PIT test to investigate whether either or both connections contributed to specific PIT performance. For a subset of these animals, levels of c-Fos in the MD and VTA were also assessed to examine changes in circuit-related c-Fos expression induced by VP-m inactivation.

\section{Subjects}

A total of 114 experimentally naive male Long-Evans rats obtained from the Laboratory Animal Services (University of Sydney, Australia) were used as subjects in Experiments 1 and 2. Animals were housed in pairs or threes in a climate-controlled colony room and were maintained on a $12 \mathrm{~h}$ light/dark cycle. Animals were handled daily for $5 \mathrm{~d}$ before training or surgery. During training and testing, animals were kept on a food deprivation schedule to maintain them at $\sim 85 \%$ of their free-feeding weight. The Animal Ethics Committee at the University of Sydney approved all experimental procedures.

\section{Apparatus \\ Training and testing for took place in 16 operant chambers (Med Asso- ciates) enclosed in sound- and light-attenuating shells. Each operant chamber was equipped with a pellet dispenser and a pump fitted with a syringe that, when activated, delivered a $45 \mathrm{mg}$ grain pellet (Bio-Serv) or $0.1 \mathrm{ml}$ of a $20 \%$ sucrose solution, respectively, into a recessed food mag- azine inside the chamber where an infrared beam crossed the magazine to detect head entries. The chambers were fitted with two retractable levers that could be inserted to the left and the right of the magazine. Each chamber also had a $3 \mathrm{~W}, 24 \mathrm{~V}$ house light that provided illumination inside the enclosed chamber, a white noise generator, and a $28 \mathrm{~V} \mathrm{DC}$ mechanical relay that delivered a $2 \mathrm{~Hz}$ clicker stimulus. Two microcom- puters running Med Associates propriety software controlled all experi- mental events and recorded responses.}

\section{Surgery}

Animals received stereotaxic surgery conducted under isoflurane anesthesia (5\% induction; $1-2 \%$ maintenance). Animals were placed in a stereotaxic frame (Kopf Instruments) and received a subcutaneous injection of $0.1 \mathrm{ml}$ of Rimadyl and also a $0.1 \mathrm{ml}$ injection of bupivicane hydrochloride at the incision site. An incision was made to expose the scalp and the incisor bar was adjusted to align bregma and lambda on the same horizontal plane. Small holes were drilled above the targeted coordinates (relative to bregma and skull) of the MD: AP: $-2.5 \mathrm{~mm}$; ML: $+0.7 \mathrm{~mm}$; DV: $-5.95 \mathrm{~mm}$ and VTA: AP: $-5.3 \mathrm{~mm}$; ML: $+0.8 \mathrm{~mm}$, DV: $-8.25 \mathrm{~mm}$ based on the approximate locations according to the rat atlas (Paxinos and Watson, 2007) and pilot surgeries. After surgery, all rats were given a $0.4 \mathrm{ml}$ intraperitoneal injection of procaine penicillin solution $(300 \mathrm{mg} / \mathrm{kg})$ and $3 \mathrm{~d}$ to recover.

In Experiment 1, surgeries were conducted before training and were staggered such that every animal had the same number of days of tract tracing. Animals $(n=53)$ received an injection of CTb $(50.6 \mathrm{nl}$ of a $1 \%$ solution diluted in deionized water) unilaterally into the MD and also a unilateral injection of FG ( $50.6 \mathrm{nl}$ of a $3 \%$ solution diluted in $0.9 \%$ saline) into the VTA. Injections were made with a nanoliter injector using glass pipettes with a diameter of $\sim 5-10 \mu \mathrm{m}$ at $23 \mathrm{nl} / \mathrm{s}$. The injector was left in place for a further 5 min before being retracted to allow for diffusion of the tracer and to reduce any leakage while retracting the pipette.

In Experiment 2, animals received either a unilateral excitotoxic lesion to the MD $(n=30)$ or the VTA $(n=31)$. Using a $1 \mu$ l Hamilton syringe connected to an infusion pump, lesions to the MD were made by a $0.4 \mu \mathrm{l}$ infusion of NMDA at a concentration of $10 \mathrm{mg} / \mathrm{ml}$ over $4 \mathrm{~min}$ and lesions to the VTA were made by infusing $0.2 \mu \mathrm{l}$ of NMDA at a concentration of $10 \mathrm{mg} / \mathrm{ml}$ over $4 \mathrm{~min}$. The syringe was further left in place for an additional 5 min before being retracted to allow for diffusion of the drug. Subsequently, all animals had guide cannulae implanted bilaterally to the VP-m; Single 26-gauge guide cannulae (Plastics One) were implanted into each hemisphere using 2 sets of coordinates relative to bregma and skull: on the left: AP: $+0.4 \mathrm{~mm}$; ML: $+1.6 \mathrm{~mm}, \mathrm{DV}:-7.2 \mathrm{~mm}$, and on the right: AP: $+0.4 \mathrm{~mm}, \mathrm{ML}:-3.1 \mathrm{~mm}, \mathrm{DV}:-7.3 \mathrm{~mm}$ at a $10^{\circ}$ angle toward the midline. The DV coordinates of the guide cannulae were made $1 \mathrm{~mm}$ above the intended infusion site (DV: $-8.2 \mathrm{~mm}$ on the left, $-8.3 \mathrm{~mm}$ on the right) and were held in place with screws and dental cement. A dummy cannula was kept in the guide at all times except during the microinfusions. To reduce the amount of time that the cannulae were implanted, animals received surgery after day 7 of instrumental training and received the remaining 3 sessions of instrumental training after recovery.

\section{Microinfusions}

In Experiment 2, the $\mathrm{GABA}_{\mathrm{A}}$ agonist muscimol (MUS) was dissolved in $0.9 \%$ saline to a final concentration of $0.5 \mathrm{mg} / \mathrm{ml}$. Animals received either a $0.2 \mu \mathrm{l}$ infusion of MUS or of saline vehicle (VEH) into the VP-m either ipsilateral or contralateral to the lesion. Microinfusions were delivered in containers in a room separated from the colony and testing rooms. Animals were preexposed to the infusion room for $2 \mathrm{~d}$ before the day of test and placed in containers for $15 \mathrm{~min}$ each day. At the time of infusion, the dummy cannula of the infusion side was removed and the infusion cannula was lowered in to the guide extending $1 \mathrm{~mm}$ below the guide tip. Infusion cannulae were connected to $25 \mu$ l Hamilton syringes fitted on an infusion pump that delivered the drug or vehicle at a rate of 0.1 $\mu \mathrm{l} / \mathrm{min}$. The infusion cannula was left in place for an additional $2 \mathrm{~min}$ before being removed and replaced by the dummy cannula. Animals were generally allowed to move freely in the containers during the infusion and the infusion cannula was constantly monitored to ensure that it did not move out of place. Animals that frequently attempted to remove the infusion cannula were handled during the infusion instead of being placed in the container. Rats were returned to their home cages for 15 min before testing. No gross motor deficits were observed in any animal after an infusion into either hemisphere.

\section{Behavioral procedures}

Pavlovian training. All animals first received Pavlovian training over eight daily sessions. Each session was $60 \mathrm{~min}$ in duration, during which animals received 2 min presentations of 2 CS (white noise and clicker), each paired with the delivery of a different outcome (sucrose or pellets) at a random time $30 \mathrm{~s}$ schedule throughout the CS. Each CS was presented 4 times in a pseudorandom order with a variable intertrial interval (ITI) that averaged $5 \mathrm{~min}$. The CS-outcome relationships were counterbalanced such that half of the animals received the white noise paired with pellets and clicker paired with sucrose solution and the other half received white noise paired with sucrose solution and clicker paired with pellets. Magazine entries throughout the session were recorded and separated into a CS period and an interval before CS presentations of equal length (Pre-CS; $2 \mathrm{~min}$ ). The rate of magazine entries for each session was averaged across the two CS. 
Instrumental training. After Pavlovian training, animals received instrumental training sessions over $10 \mathrm{~d}$. In each daily session, animals were trained to perform left and right lever press responses for the different outcomes (sucrose or pellets) separately. Training on each lever ended when 20 outcomes had been earned or after $30 \mathrm{~min}$ had elapsed. The order of the lever presentations alternated each day and responseoutcome pairings were counterbalanced with CS-outcome pairings such that half of each group received pellets for left lever press responses and sucrose for right lever press responses and the other half of each group received the opposite pairings. The initial two sessions of lever press training were continuously reinforced such that each lever press earned an outcome. In subsequent training sessions the probability of reinforcement $(p)$ shifted to a random ratio $(\mathrm{RR})$ schedule: a RR5 $(p=0.2)$ schedule was used in sessions $3-5$ and a RR10 $(p=0.1)$ schedule was used in sessions $6-10$. The rate of responding on the levers for each session was recorded and averaged across the two levers.

Specific Pavlovian-instrumental transfer. After Pavlovian and instrumental conditioning, animals were given a test of specific PIT performance. During the test, both levers remained inserted into the chamber throughout and lever presses were recorded but no outcomes were delivered. Responding on the levers was first extinguished in the absence of the cues for $8 \mathrm{~min}$, after which each CS was presented 4 times over the next $40 \mathrm{~min}$ in the following order: clicker-noise-noise-clicker-noiseclicker-clicker-noise. Each CS lasted $2 \mathrm{~min}$ and was presented at a fixed ITI of $3 \mathrm{~min}$. Magazine entries and lever-pressing rates were recorded throughout the session.

In Experiment 1, animals were divided based on their training performance into three groups where one group of animals received a specific PIT test (Group PIT), one group of animals was given access to both levers but did not receive any presentations of the CS (Group LP), and a third group of animals received the same presentations of the CS at the same time as presented during the specific PIT test but with the levers retracted (Group CS). All test conditions were conducted in the absence of any outcomes and Group LP was tested separately to avoid any influences of the CS. Magazine entries for Group PIT and Group CS were separated into responses during the Pre-CS and CS periods and responding on the levers for Group PIT was also separated into lever presses during the Pre-CS period and during the CS period on the lever with which it shared the same outcome the CS predicted and responding on the lever that shared a different outcome the CS predicted.

In Experiment 2, all animals received a specific PIT test. Before the test, animals were either given an infusion of VEH into the VP-m on the ipsilateral or contralateral side of the lesion (MDs, $n=6$; VTAs, $n=6$ ), an infusion of MUS in the VP-m on the ipsilateral hemisphere of the lesion (MDi, $n=12$; VTAi, $n=12$ ), or an infusion of MUS in the VP-m on the contralateral hemisphere of the lesion (MDc, $n=12$; VTAc, $n=$ 13), thus creating six groups. Twenty-four rats receiving an infusion of MUS into the VP-m (MDi, $n=6$; VTAi, $n=6$; MDc, $n=6$; VTAc, $n=$ 6) were perfused $120 \mathrm{~min}$ from the start of the test for the assessment of c-Fos expression.

\section{Histology}

$\mathrm{CTb}$ and FG injection sites. Animals in Experiment 1 were transcardially perfused with a 4\% PFA in PBS (0.1 M, pH 7.2) solution 120 min from the start of the test. Brains were extracted and left in PFA overnight before sections were collected on a vibratome (VT1000; Leica) and stored in a cryoprotectant at $-20^{\circ} \mathrm{C}$. Coronal sections containing injection sites were collected at $50 \mu \mathrm{m}$ and all other regions were collected at $30 \mu \mathrm{m}$.

To locate the injection sites, sections containing the MD were stained using a goat anti-CTb antibody for visualization of the injection site. Sections were first rinsed 3 times for $10 \mathrm{~min}$ in PBS and then incubated for $2 \mathrm{~h}$ in $10 \%$ normal horse serum (NHS) and $0.5 \%$ Triton $\mathrm{X}-100$ (TX-100) diluted in PBS. After, sections were incubated for $48 \mathrm{~h}$ in $4^{\circ} \mathrm{C}$ in a solution containing the anti-CTb antibody (1:2000, catalog \#703; List Biological Laboratories), 2\% NHS, and 0.2\% TX-100 in PBS. Sections were then washed three times for $10 \mathrm{~min}$ in PBS and incubated for $90 \mathrm{~min}$ in a solution containing an Alexa Fluor 488 donkey anti-goat secondary antibody (1:1000, catalog \#A11055; Invitrogen), 2\% NHS, and 0.2\% TX100 in PBS. Sections were rinsed a final three times in PBS and mounted on slides and coverslipped with Fluoromount-G (Southern Biotechnology). VTA sections containing the FG injection site were mounted directly on slides and coverslipped after three 10 min washes in PBS. Placements of each injection site were then observed using an Olympus FV10i confocal microscope and animals with a misplaced injection to either structure were excluded from further analyses.

Lesion and cannulae placements. Animals in Experiment 2 were transcardially perfused with $4 \%$ PFA. Cannulae were removed after perfusion and brains were extracted and left in PFA overnight. For animals that were perfused $120 \mathrm{~min}$ from the start of the test, $30 \mu \mathrm{m}$ coronal sections were collected on a vibratome. For all other animals, brains were transferred to $30 \%$ sucrose solution for $3 \mathrm{~d}$ and $40 \mu \mathrm{m}$ coronal sections were collected on a cryostat (CM1850; Leica). Subsequently, sections of the VP-m were mounted on slides and stained with cresyl violet for visualization of cannula placements. Using identical immunohistological procedures, sections containing the MD or VTA lesion were stained with a red fluorescent Nissl stain (1:500, catalog \#N21482; Invitrogen) and the astrocyte marker glial fibrillary acidic protein (GFAP), which can localize the extent of astrocytic proliferation due to inflammation caused by a lesion. For this, a rabbit anti-GFAP antibody (1:1000, catalog \#AB7260; Abcam) was paired with an Alexa Fluor 488 donkey anti-rabbit secondary antibody (1:1000; Invitrogen. A21206). Cannula placements were observed under an Olympus BX50 light microscope and lesion placements were observed under an Olympus FV10i fluorescence confocal microscope. Animals with a misplaced lesion or cannula were excluded from behavioral analyses.

\section{Immunofluorescence and neuronal analysis}

In Experiment 1, using the same protocol described previously, sections containing the VP-m at the approximate coronal level of +0.36 from bregma (Paxinos and Watson, 2007) were processed for both c-Fos and CTb using a rabbit anti-c-Fos (1:500, catalog \#sc-52; Santa Cruz Biotechnology) and the goat anti-CTb antibodies. Secondary antibodies used were an Alexa Fluor 546 donkey anti-rabbit antibody (1:1000, catalog \#A10040; Invitrogen) and an Alexa Fluor 488 donkey anti-goat (1:1000). Sections were then observed under an Olympus BX61W1 confocal microscope and a $10 \times$ confocal image containing the VP-m was taken for each section for the quantification of neurons labeled with $\mathrm{CTb}\left(\mathrm{CTb}^{+}\right)$, neurons positive for $\mathrm{FG}\left(\mathrm{FG}^{+}\right)$, neurons colabeled with $\mathrm{CTb}$ and $\mathrm{FG}$ $\left(\mathrm{CTb}^{+} \mathrm{FG}^{+}\right)$, neurons labeled with c-Fos $\left(\mathrm{c}-\mathrm{Fos}^{+}\right)$, neurons colabeled for FG and c-Fos $\left(\mathrm{FG}^{+} \mathrm{Fos}^{+}\right)$, neurons colabeled for CTb and c-Fos $\left(\mathrm{CTb}^{+} \mathrm{Fos}^{+}\right)$, and neurons triple-labeled for $\mathrm{CTb}, \mathrm{FG}$, and $\mathrm{c}-\mathrm{Fos}$ $\left(\mathrm{CTb}^{+} \mathrm{FG}^{+} \mathrm{Fos}^{+}\right) . \mathrm{CTb}^{+} \mathrm{FG}^{+}$neurons were counted as a separate population and therefore any neuron that was colabeled for both tracers were deducted from the single labeled population. A region of interest (ROI) within the VP-m for each section was outline and measured and quantifications were conducted manually using ImageJ software by an observer blinded to the group allocations to avoid any biasing effects. The total number of neurons was then converted to an estimate of neurons per square millimeter using the area of the ROI for statistical analyses.

In Experiment 2, sections containing the MD and VTA at the approximate coronal level of $-2.52 \mathrm{~mm}$ and $-5.28 \mathrm{~mm}$ from bregma, respectively (Paxinos and Watson, 2007), were processed for c-Fos immunoreactivity using the rabbit anti-c-Fos antibody (1:500). A mouse anti-tyrosine hydroxylase antibody (TH) (1:5000, catalog \#T2928; Sigma-Aldrich) was also added for labeling dopaminergic (DA) neurons. Secondary antibodies used were an Alexa Fluor 546 donkey anti-rabbit (1:1000) and an Alexa Fluor 488 donkey anti-mouse (1:1000, catalog \#A21202; Invitrogen). All sections were observed under an Olympus BX61W1 confocal microscope and $10 \times$ confocal images were taken for quantification of c-Fos expression. Three regions were quantified for each animal. In the structure containing a unilateral lesion, images of the hemisphere contralateral to the lesion were quantified, whereas, in the other structure where there was no lesion on either hemisphere, images of both hemispheres were quantified. For each image, an ROI within each structure was outlined and measured and all images were quantified manually using ImageJ software by an observer blinded to the treatment condition. Quantifications were expressed as average number of c-Fos ${ }^{+}$ neurons per square millimeter and neurons expressing c-Fos in the VTA 


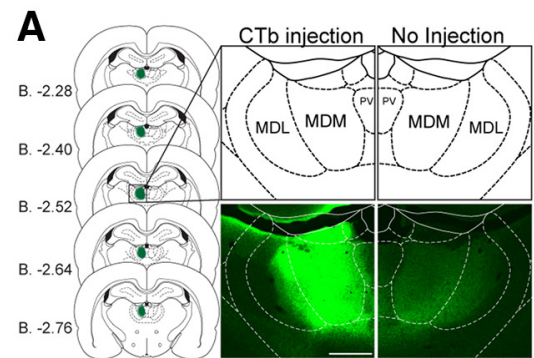

B

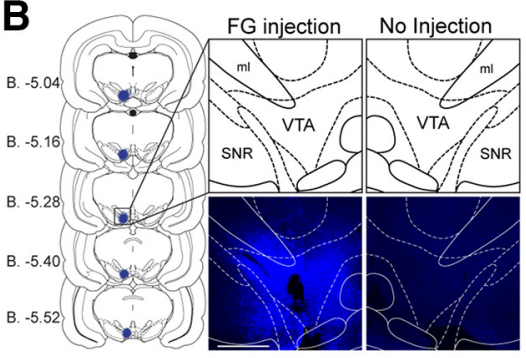

C

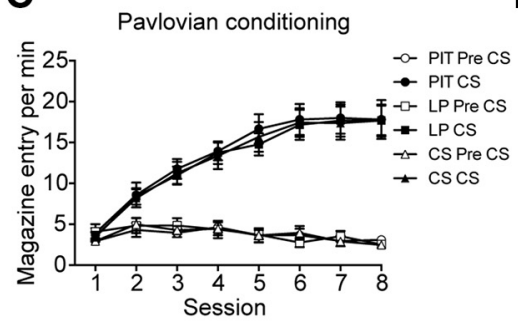

Instrumental training

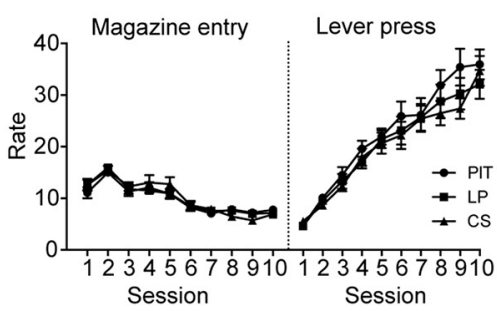

$\mathbf{E}$

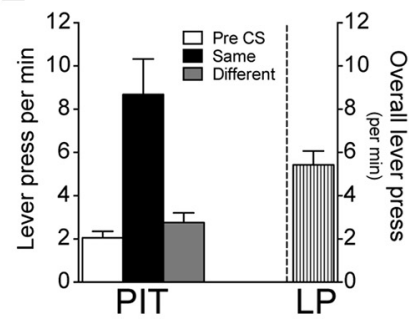

$\mathbf{F}$

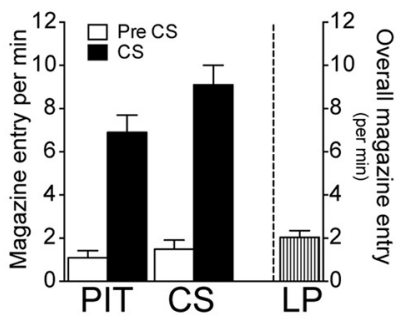

Figure 1. Experiment 1. A, B, Schematic representation of the spread of the tracer and a photomicrograph of the injection site in one hemisphere compared with the noninjected hemisphere of CTb and FG injected into the MD and ventral tegmental area, respectively (Paxinos and Watson, 2007). C, D, Pavlovian and instrumental training presented as the rate of magazine entries per minute during the Pre-CS and CS periods and magazine entries and lever presses per minute, respectively, over sessions in Groups PIT $(n=9)$, LP $(n=10)$, and CS $(n=10)$. $\boldsymbol{E}, \boldsymbol{F}$, Performance during behavioral test conditions. $\boldsymbol{E}$, Left, Lever pressing performance of Group PIT shown as lever pressing per minute during the Pre-CS period (Pre-CS) and separately during the CS period, for responding on the lever that, in training, delivered the same outcome as that predicted by the CS (Same) and on the lever that had delivered the different outcome (Different). Right, Performance of Group LP shown as lever presses per minute throughout the entire session. $F$, Left, Magazine entries per minute of Groups PIT and CS separated into Pre-CS and CS periods. Right, Magazine entries per minute for Group LP throughout the entire session. PV, Paraventricular thalamic nucleus; MDM, mediodorsal thalamus nucleus, medial part; MDL, mediodorsal thalamus nucleus, lateral part. Scale bar, $500 \mu \mathrm{m}$.

were further separated into neurons that were TH-negative $\left(\mathrm{TH}^{-}\right)$or TH-positive $\left(\mathrm{TH}^{+}\right)$.

\section{Statistical methods}

All statistical analyses were performed using the statistical software SPSS. Analyses of behavioral procedures were conducted using mixed-model ANOVA followed by simple effects analyses to establish the source of any significant interaction. Analyses of neuronal quantifications were conducted using between-subjects ANOVAs. Correlations between neuronal expression and behavioral performance were conducted using Pearson's $r$ test. Behavioral measures used for correlation with neuronal activation were as follows: (1) overall lever press rate per minute: the total lever presses on the two levers divided by the duration of the test (total lever presses/40); (2) elevation of magazine entries during the CS periods compared with Pre-CS periods calculated as an elevation ratio: magazine entries during the $\mathrm{CS}$ period divided by total magazine entries during the Pre-CS and CS periods [CS/(CS + Pre-CS)]; and (3) net PIT performance calculated as a specific PIT index: the number of responses made on the lever associated with the same outcome the CS is predicting minus baseline (Pre-CS period) minus the number of responses made on the lever associated with the different outcome the CS is predicting minus baseline responding [(Same - Pre-CS) - (Different - Pre-CS)]. Graphs were plotted using GraphPad Prism software.

\section{Results}

Experiment 1: Neuronal assessment of VP-m projections to the MD and VTA during specific PIT

Histology

Figure 1, $A$ and $B$, displays the schematic representation of the spread of the tracer injection and a representative injection of $\mathrm{CTb}$ into the MD and FG into the VTA, respectively. After excluding animals with a misplaced injection site to either structure, the number of subjects in each group were as follows: Group PIT: $n=9$, Group LP: $n=10$, Group CS: $n=10$ ).

\section{Pavlovian and instrumental training}

Injection of the tracers CTb and FG did not affect animals' ability to acquire both Pavlovian and instrumental conditioning, as shown in Figure 1, $C$ and $D$, respectively. During Pavlovian conditioning, animals were clearly able to distinguish between the Pre-CS and CS periods and the difference between head entries during the Pre-CS and CS increased over sessions. A mixed ANOVA conducted using factors of Group (PIT, LP, and CS), Session (1-8), and CS period (separating Pre-CS and CS) found an effect of Session $\left(F_{(7,182)}=28.04, p<0.001\right)$, of CS period $\left(F_{(1,26)}=255.66, p<0.001\right)$, and a Session by CS period interaction $\left(F_{(7,182)}=55.20, p<0.001\right)$. There was no significant effect of Group or any interactions involving Group as a factor (all values of $F<1$ ). During the instrumental training phase, rates of responding on the levers increased over days as the random ratio schedule increased. A mixed ANOVA conducted using factors of Group (PIT, LP, and CS) and Session (1-10) found an effect of Session $\left(F_{(9,234)}=130.37, p<0.001\right)$, but no effect of Group and no interaction between these factors (all values of $F<1$ ). Magazine entries during instrumental training decreased as the random ratio schedule increased over sessions. A mixed ANOVA conducted on magazine entries using factors of Group and Session found an effect of Session $\left(F_{(9,234)}=73.57, p<0.001\right)$, but no effect of Group or interaction between factors (largest value of $\left.F_{(18,234)}=1.37, p=0.15\right)$.

\section{Behavioral test condition}

Whereas the animals in Group PIT received the specific PIT test, the control groups received either exposure to the levers (Group LP) or to CS presentations (Group CS). Comparing the lever press performance between Groups PIT and LP, the rate of lever pressing averaged across levers over the course of the 40 min test after the extinction period was $7.65 \pm 0.85$ and $5.43 \pm 0.64$ lever presses per minute for Group PIT and Group LP (Fig. 1E, right $y$-axis), respectively. ANOVA with factors of Group (PIT and LP) and Performance revealed a significant difference in the overall rate of lever pressing between the two groups $\left(F_{(1,18)}=4.50, p=\right.$ $0.049)$. The performance of Group PIT was further analyzed with 

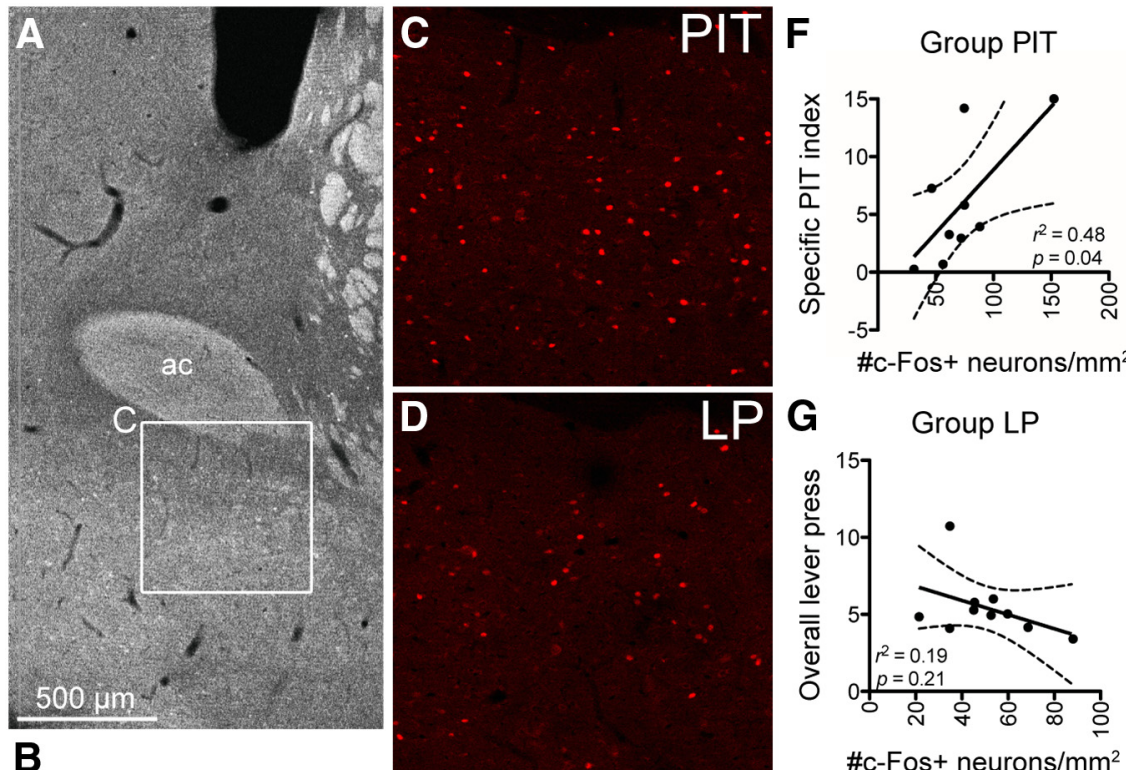

B
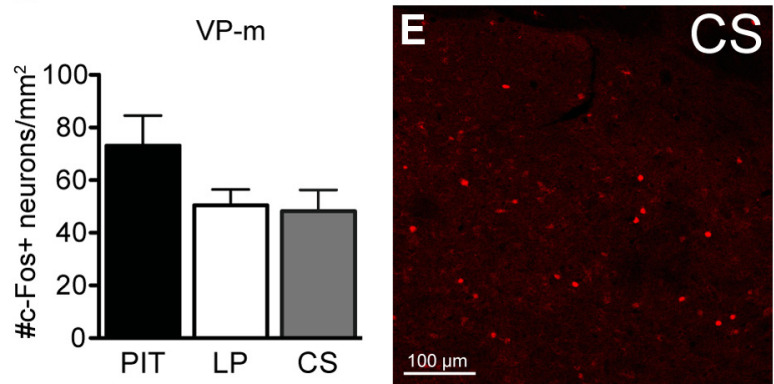

\#c-Fos+ neurons $/ \mathrm{mm}^{2}$

Group CS

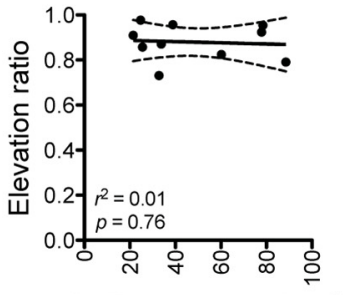

\#c-Fos+ neurons $/ \mathrm{mm}^{2}$

Figure 2. Experiment 1. c-Fos expression in the VP-m. $A$, Photomicrograph of the approximate coronal level of sections selected for quantification, with inset $(\boldsymbol{C})$ showing a region in the VP-m. $\boldsymbol{B}$, Elevation of c-Fos expression in Group PIT $(n=9)$ did not significantly differ from controls (Group LP, $n=10$; Group $C S, n=10$ ). $C-E$, Photomicrographs of c-Fos immunoreactivity in the VP-m in each behavioral condition. $\boldsymbol{F}-\boldsymbol{H}$, Pearson's correlation found c-Fos levels in Group PIT $(\boldsymbol{F})$ correlated to their net PIT performance (specific PIT index), but c-Fos expression in Groups $L P(\boldsymbol{G})$ or $C S(\boldsymbol{H})$ did not correlate with overall lever pressing or the elevation in magazine entries during $C S$ presentations, respectively. ac, Anterior commissure.

CS period as a factor and shown on the left $y$-axis in Figure $1 E$ as the rate of responding (lever press per minute), averaged across levers, during the period before CS presentation (Pre-CS), during the CS with which it shares the same outcome with a particular lever (Same), and during the CS with which it shares a different outcome with a particular lever (Different). When responding was separated into periods according to CS identity, animals in Group PIT showed a clear specific PIT effect. ANOVA conducted on CS identity (Pre-CS, Same, and Different) found a difference in responding $\left(F_{(2,16)}=12.80, p<0.001\right)$. Simple effect analyses conducted on the each level of CS identity found no differences in rates of responding between Pre-CS and Different $\left(F_{(1,8)}=2.82\right.$, $p=0.13)$, but an increase in responding during the Same over Pre-CS $\left(F_{(1,8)}=15.63, p=0.004\right)$ and Different $\left(F_{(1,8)}=10.89\right.$, $p=0.01)$.

We also analyzed magazine entries. ANOVA conducted on the overall magazine entries for all groups found an effect of Group $\left(F_{(2,26)}=8.78, p=0.001\right)$, with no difference in magazine entries between Groups PIT and CS $\left(F_{(1,17)}=1.54, p=0.23\right)$, but Group LP (Fig. $1 F$, right $y$-axis) made significantly fewer magazine entries compared with Group CS $\left(F_{(1,18)}=13.18, p=0.002\right)$ and Group PIT $\left(F_{(1,17)}=15.38, p=0.001\right)$. Magazine entries for Groups PIT and CS were further analyzed with CS period (separating Pre-CS and CS periods) as a factor. The left $y$-axis on Figure $1 F$ shows the magazine entry during the Pre-CS and CS

period for the two groups, both demonstrating robust conditioned responding during the presentations of the CS. Confirming the observations with statistical analyses, a mixed ANOVA conducted using factors of CS period and Group found an effect of CS period $\left(F_{(1,17)}=117.01\right.$, $p<0.001)$, but no effect of Group $\left(F_{(1,17)}\right.$ $=3.27, p=0.09)$ or interaction between factors $\left(F_{(1,25)}=2.12, p=0.16\right)$. Further analyses conducted in each group found a significant increase in magazine entries during the CS period in Group PIT $\left(F_{(1,8)}\right.$ $=31.38, p<0.001)$ and Group CS $\left(F_{(1,9)}\right.$ $=111.96, p<0.001)$.

\section{Overall $c$-Fos activation in the VP-m}

Figure $2 A$ shows the approximate coronal level at which sections were selected for quantifications of c-Fos expression in the VP-m and examples of the overall level of c-Fos expression in each group are presented in Figure 2, $C-E$. Three sections per animal were quantified and the overall c-Fos expression across groups is presented in Figure $2 B$. Although there seems to be an elevated level of c-Fos in Group PIT, similar to that we previously reported (Leung and Balleine, 2013), ANOVA conducted on the average number of c-Fos ${ }^{+}$neurons per square millimeter found no significant differences between groups $\left(F_{(2,26)}=2.49, p=0.10\right)$. Simple effects analysis conducted to compare each individual Group found no difference between Group PIT and Group CS $\left(F_{(1,17)}=3.28, p=0.09\right)$ or Group LP $\left(F_{(1,17)}=3.29, p=0.09\right)$; there was also no difference between the two control Groups LP and CS $\left(F_{(1,18)}=0.05, p=0.83\right)$. However, as shown in Figure $2 F$, Pearson's correlations between the neuronal expression and behavior revealed a significant correlation between c-Fos expression and net PIT performance $(r=0.70, p=0.04)$ in Group PIT. In contrast, there was no correlation between c-Fos expression and overall lever press rate in Group LP (Fig. 2G; $r=$ $-0.43, p=0.21$ ) or between $c$-Fos expression and the elevation ratio in conditioned responding during the CS in Group CS (Fig. $2 H ; r=-0.11, p=0.76)$.

$c$-Fos expression in MD- and VTA-projecting neurons

Dense labeling with $\mathrm{CTb}$ and FG (i.e., neurons projecting to the MD or VTA, respectively) was observed in the VP-m. In addition, there was a small proportion of neurons that was colabeled with $\mathrm{CTb}$ and FG, indicating that these neurons projected to both the $\mathrm{MD}$ and VTA. As shown in Table 1, the number of neurons labeled by each tracer was comparable between groups. ANOVA conducted on average neurons per square millimeter found no differences between groups in the number of neurons positive for $\operatorname{CTb}\left(F_{(2,26)}=0.78, p=0.47\right), \mathrm{FG}\left(F_{(2,26)}=2.12, p=0.14\right)$, or for $\mathrm{CTb}+\mathrm{FG}\left(F_{(2,26)}=0.44, p=0.65\right)$.

For analyzing c-Fos ${ }^{+}$neurons that were colabeled with $\mathrm{CTb}$, $\mathrm{FG}$, or $\mathrm{CTb}+\mathrm{FG}$, the percentage of each population of neurons expressing c-Fos was calculated from the average neurons per square millimeter. Examples of colabeling in the VP-m and the 
percentage of neurons in each population expressing c-Fos are displayed in Figure 3. ANOVA conducted on each population found no differences in the percentage of c-Fos expression between groups in neurons projecting to the VTA $\left(\% \mathrm{FG}^{+} \mathrm{Fos}^{+}\right.$; $\left.F_{(2,26)}=2.28, p=0.12\right)$, but a significant difference between groups in neurons projection to the $\mathrm{MD}\left(\% \mathrm{CTb}^{+} \mathrm{Fos}^{+} ; F_{(2,26)}=6.19\right.$, $p=0.01)$ and a significant difference between groups in neurons projection to both structures $\left(\% \mathrm{CTb}^{+} \mathrm{FG}^{+} \mathrm{Fos}^{+} ; F_{(2,26)}=4.91\right.$, $p=0.02)$.

Simple effects analyses were conducted to compare each group individually. For neurons in the VP-m projecting to the VTA, there was no difference in c-Fos expression between Group PIT and Group $\operatorname{LP}\left(F_{(1,17)}=0.69, p=0.42\right)$ and also no difference between Group LP and Group $\operatorname{CS}\left(F_{(1,18)}=1.75, p=0.20\right)$. However, there were significantly more neurons projecting to the VTA expressing c-Fos in Group PIT than in Group CS $\left(F_{(1,17)}=\right.$ $5.07, p=0.04)$. Comparable analyses conducted on the percentage of c-Fosexpressing neurons projecting to the MD revealed a higher percentage of neurons expressing c-Fos in Group PIT than in Group LP $\left(F_{(1,17)}=9.91, p=0.006\right)$ or in Group CS $\left(F_{(1,17)}=6.50, p=0.02\right)$, but no significant difference between Groups LP and CS $\left(F_{(1,18)}=0.04, p=0.84\right)$. Similarly, analysis of the percentage of neurons expressing c-Fos projecting to both the MD and VTA found no difference in c-Fos expression between Groups LP and CS $\left(F_{(1,18)}=0.42, p=\right.$ $0.53)$, but an increase in c-Fos expression in Group PIT compared with Group LP $\left(F_{(1,17)}=4.61, p=0.046\right)$ and Group $\operatorname{CS}\left(F_{(1,17)}=\right.$ 7.37, $p=0.02)$.

Finally, Pearson's correlation between populations of neurons expressing c-Fos and behavioral performance in each behavioral test condition detected no significant correlations in Group LP or Group CS. However, in Group PIT, the percentage of neurons projecting to the VTA expressing c-Fos was found to correlate with the net PIT performance $(r=0.72, p=0.03)$. This was not observed in c-Fos activated neurons projecting to the $\mathrm{MD}(r=$ $0.49, p=0.18)$ or to both the MD and VTA $(r=0.64, p=0.06)$.

Experiment 2: Effect of disconnection of the VP-m and MD or VTA on specific PIT

Histology

A schematic representation of cannulae placements in targeted region of the VP-m is displayed in Figure $4 A$ with a representative image of guide cannulae track marks. Figure $4, B$ and $C$, display a schematic representation of the extent of the lesion as well as a representative lesion in each site labeled using fluorescent Nissl and GFAP in the MD and VTA, respectively. After the exclusion of animals with a misplaced guide cannula in the infusion hemisphere or a lesion that was not in the targeted region, the number of animals in each group separated as lesion and infusion hemisphere were as follows: MDc, $n=7$; MDi, $n=7$; MDs, $n=4$; VTAc, $n=7$; VTAi, $n=9$; VTAs, $n=4$.
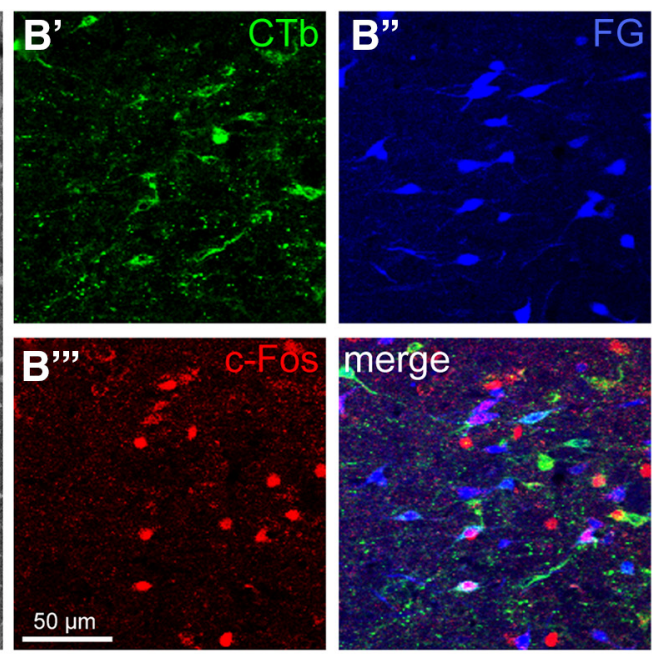

C Neurons projecting to MD

Neurons projecting to VTA Neurons projecting to MD and VTA

Figure 3. Experiment 1. Quantification of c-Fos expression of neurons in the VP-m projecting to the MD, VTA, or to both structures. $\boldsymbol{A}$, Photomicrograph of a section containing the VP-m (inset, $\boldsymbol{B}$ ). $\boldsymbol{B}$, Immunofluorescence in the VP-m showing cells 政, neurons projecting to the VTA (Center, $\% \mathrm{FG}^{+} \mathrm{Fos}^{+}$) alone did not differ between Groups PIT and LP, but was higher compared with Group CS. ac, Anterior commissure; CPu, caudate putamen.

\section{Pavlovian and instrumental training}

Animals in Group MDs and Group VTAs were first compared across all training procedures to combine the two groups as one control group where animals received only saline infusions into the VP-m. ANOVA conducted on Group MDs and Group VTAs found no differences between the two groups in Pavlovian conditioning (largest $F_{(7,42)}=1.51, p=0.19$ ) or instrumental conditioning (largest $\left.F_{(9,54)}=1.95, p=0.06\right)$.

All groups were able to show Pavlovian conditioning over the course of training (data not shown). A mixed ANOVA conducted on factors of Group (MDs/VTAs, MDi, MDc, VTAi and VTAc), Session, and CS Period found no significant effect of Group $\left(F_{(4,33)}=\right.$ $0.83, p=0.51$ ) or interactions involving Group as a factor (largest $\left.F_{(4,33)}=2.24, p=0.09\right)$, but did find a significant effect of Session $\left(F_{(7,231)}=40.01, p<0.001\right)$, a significant effect of CS Period $\left(F_{(1,33)}\right.$ $=525.82, p<0.001)$, and a significant CS Period by Session interaction $\left(F_{(7,231)}=69.97, p<0.001\right)$. Performance during instrumental training was also similar across groups, and animals continued to increase their rate of responding on the levers after surgery (data not shown). An ANOVA conducted using Group (MDs/VTAs, MDi, MDc, VTAi and VTAc) and Session as factors found an effect of Session $\left(F_{(9,297)}=104.56, p<0.001\right)$, but neither an effect of Group $\left(F_{(4,33)}=0.53, p=0.71\right)$ nor an interaction between Session and Group $\left(F_{(36,297)}=0.68, p=0.92\right)$.

\section{Specific PIT}

The necessity of the VP-m to MD and VP-m to VTA connection for specific PIT was assessed by inactivating the VP-m in the 
Table 1. Experiment 1: total number of c-Fos positive neurons and average number of neurons per square millimeter in the VP-m during specific PIT and the proportion of c-Fos-positive neurons retrogradely labeled with CTb infused into the MD or FG into the VTA

\begin{tabular}{|c|c|c|c|c|c|c|}
\hline \multirow[b]{2}{*}{ Group } & \multicolumn{3}{|c|}{ Total number of neurons $^{a}$} & \multicolumn{3}{|c|}{ Average per $\mathrm{mm}^{2}$} \\
\hline & PIT & LP & CS & PIT & $\mathrm{LP}$ & CS \\
\hline $\mathrm{CTb}^{+}$ & $119.33(5.36)$ & $113.30(7.78)$ & 111.30 (4.94) & $139.58(9.00)$ & $127.03(12.05)$ & $123.07(6.80)$ \\
\hline $\mathrm{FG}^{+}$ & $140.11(4.01)$ & $133.10(5.09)$ & $129.10(9.28)$ & $161.58(8.66)$ & $145.66(7.15)$ & $138.20(8.42)$ \\
\hline $\mathrm{CTb}^{+} \mathrm{FG}^{+}$ & $14.66(2.58)$ & $13.60(1.76)$ & $12.30(1.65)$ & $15.15(2.99)$ & $13.41(2.15)$ & $12.12(1.63)$ \\
\hline $\mathrm{c}-\mathrm{Fos}^{+}$ & $70.67(12.18)$ & $50.40(5.02)$ & $47.80(7.41)$ & $73.14(11.42)$ & $50.43(6.00)$ & $48.22(8.09)$ \\
\hline $\mathrm{CTb}^{+} \mathrm{Fos}^{+}$ & $6.89(1.46)$ & $2.80(0.70)$ & $3.00(1.15)$ & $9.23(1.58)$ & $3.54(0.80)$ & $3.85(1.23)$ \\
\hline $\mathrm{FG}^{+} \mathrm{Fos}^{+}$ & $5.33(1.17)$ & $4.90(1.08)$ & $2.90(0.90)$ & 7.64 (1.14) & $5.67(1.21)$ & $3.69(0.89)$ \\
\hline $\mathrm{CTb}^{+} \mathrm{FG}^{+} \mathrm{Fos}^{+}$ & $2.00(0.33)$ & $0.70(0.21)$ & $0.80(0.29)$ & $2.13(0.38)$ & $0.69(0.38)$ & $0.80(0.29)$ \\
\hline$\% \mathrm{CTb}^{+} \mathrm{Fos}^{+}$ & $5.63(1.22)$ & $2.29(0.51)$ & $2.57(0.90)$ & $6.56(1.20)$ & $2.68(0.46)$ & $2.88(0.85)$ \\
\hline$\% \mathrm{FG}^{+} \mathrm{Fos}^{+}$ & $3.85(0.87)$ & $3.78(0.88)$ & $2.17(0.63)$ & $4.89(0.90)$ & $3.89(0.83)$ & $2.57(0.55)$ \\
\hline$\% \mathrm{CTb}^{+} \mathrm{FG}^{+} \mathrm{Fos}^{+}$ & $17.10(3.47)$ & $6.28(2.04)$ & $5.27(2.03)$ & $19.38(5.02)$ & $7.45(2.73)$ & $5.24(2.02)$ \\
\hline
\end{tabular}

Values represent mean (SEM).

${ }^{a}$ Group means of the sum of three sections.

hemisphere contralateral to the lesion in Group MDc and Group VTAc, respectively. This was compared with groups that had the VP-m inactivated in the hemisphere ipsilateral to the lesion; that is, Groups MDi and VTAi, which had one hemisphere intact, and the control group that received a vehicle infusion into the VP-m (Group MDs and Group VTAs).

The test results from Group MDs and Group VTAs were first analyzed to combine the two groups as one control where rats received no inactivation of the VP-m. Performance during the test for both groups was similar; there were no differences between having a unilateral lesion to the MD or VTA and both groups showed a comparable specific PIT effect. ANOVA conducted on factors of Group (MDs and VTAs) and CS identity (separating Pre-CS, Same, and Different) for lever pressing found an effect of CS identity $\left(F_{(2,12)}=19.31, p<0.001\right)$, but no effect of Group $\left(F_{(1,6)}=0.56, p=0.48\right)$ and no interaction between these factors $\left(F_{(2,12)}=0.18, p=0.84\right)$.

The lever press performance during the test for Groups MDs/ VTAs, MDi, MDc, VTAi, and VTAc is presented in Figure $5 A$, separated into responding based on CS identity, and Figure $5 B$, separated into responding on the Same and Different lever during the CS presentations minus Pre-CS responding. It is clear from both figures that animals that received an infusion of $\mathrm{VEH}$ into the VP-m but with a lesion to either the MD or VTA were able to demonstrate a clear specific PIT effect. Similarly, animals that received an infusion of MUS into the VP-m on the side ipsilateral to the lesion also appeared able to demonstrate a specific PIT effect, although they exhibited a moderate reduction in overall responding. However, responding in animals that received an infusion of MUS contralateral to the lesion appeared to show a deficit in specific PIT, although the deficit appeared to differ depending on the site of the lesion. An ANOVA conducted using Group (MDs/VTAs, MDi, MDc, VTAi, VTAc) and CS identity (separating Pre-CS, Same, and Different) as factors found an effect of Group $\left(F_{(4,33)}=3.63, p=0.02\right)$, CS identity $\left(F_{(2,66)}=55.05, p<0.001\right)$, and an interaction between these factors $\left(F_{(8,66)}=5.71, p<0.001\right)$. Simple effects analysis conducted on each individual group found an effect of CS identity in Group MDs/VTAs $\left(F_{(2,14)}=21.89, p<0.001\right)$, Group MDi $\left(F_{(2,12)}=7.74, p=0.01\right)$, Group $\operatorname{MDc}\left(F_{(2,12)}=26.31, p<\right.$ $0.001)$, Group VTAi $\left(F_{(2,16)}=10.94, p=0.001\right)$, and Group $\operatorname{VTAc}\left(F_{(2,12)}=10.35, p=0.002\right)$. Further analyses conducted on each level of CS identity found that Group MDs/VTAs was able to show normal specific PIT; animals responded more on the action that in training delivered the same outcome as that signaled by the CS (i.e., Same) relative to the Pre-CS period $\left(F_{(1,7)}=23.45\right.$, $p=0.002)$ and to the other (i.e., Different) action $\left(F_{(1,7)}=22.93\right.$, $p=0.002)$. There was no difference between Pre-CS and Different $\left(F_{(1,7)}=0.001, p=0.98\right)$. A similar pattern of results was found in Groups MDi, VTAi, and VTAc. Group MDi responded more on Same than Pre-CS $\left(F_{(1,6)}=15.72, p=0.007\right)$ and Different $\left(F_{(1,6)}=6.06, p=0.049\right)$, with no difference in responding between Pre-CS and Different $\left(F_{(1,6)}=0.62, p=0.46\right)$. Group VTAi animals also responded more on Same than Pre-CS $\left(F_{(1,8)}=\right.$ $27.30, p=0.001)$ and Different $\left(F_{(1,8)}=8.39, p=0.02\right)$ and showed no difference in responding between Different and Pre-CS $\left(F_{(1,8)}\right.$ $=0.38, p=0.56)$. Group VTAc showed higher responding on Same than Pre-CS $\left(F_{(1,6)}=13.20, p=0.01\right)$ and Different $\left(F_{(1,6)}\right.$ $=8.33, p=0.03)$ and responding between Pre-CS and Different did not differ $\left(F_{(1,6)}=4.72, p=0.07\right)$, surprisingly indicating a specific PIT effect. Conversely, Group MDc demonstrated a different pattern of responding. Whereas animals in Group MDc responded more on Same than Pre-CS $\left(F_{(1,6)}=60.62, p<0.001\right)$, these animals also responded more on Different than Pre-CS $\left(F_{(1,6)}=19.99, p=0.004\right)$ and the level of responding between Same and Different did not differ $\left(F_{(1,6)}=2.71, p=0.15\right)$, suggesting that the CS elevated performance over baseline but in an undifferentiated manner.

Although the rats in Group VTAc appeared to be able to demonstrate a specific PIT effect, their performance differed from the other groups showing this effect: the rats in this group showed a much higher level of lever pressing during the Pre-CS period than all other groups. ANOVA conducted on responding during the Pre-CS period revealed a difference between groups $\left(F_{(4,33)}=\right.$ $4.48, p=0.005)$. Simple effect analysis further revealed that animals in Group VTAc responded significantly more during the Pre-CS period than Group MDs/VTAs $\left(F_{(1,13)}=5.75, p=0.03\right)$, Group $\operatorname{MDi}\left(F_{(1,12)}=9.19, p=0.01\right)$, and $\operatorname{Group} \operatorname{VTAi}\left(F_{(1,14)}=\right.$ $8.01, p=0.01)$, all of which demonstrated normal specific PIT. As no outcomes are delivered, performance is typically extinguishing during the specific PIT test. As such, the high level of Pre-CS responding in Group VTAc may have stemmed from a deficit in the extinction of lever pressing after disconnection of the VP and the VTA. Therefore, the rate of extinction during the initial $8 \mathrm{~min}$ in the absence of the CS was analyzed. Figure $5 C$ shows the total presses on both levers during the 8 min extinction period during the specific PIT test before the first CS presentation. Several things are clear from this figure. First, although responding in Group MDs/VTAs was clearly higher early in extinction, responding in Group VTAc was similar in extinction to other groups that received an infusion of MUS. It is also clear from this figure that all groups, including Group VTAc, do extinguish their 

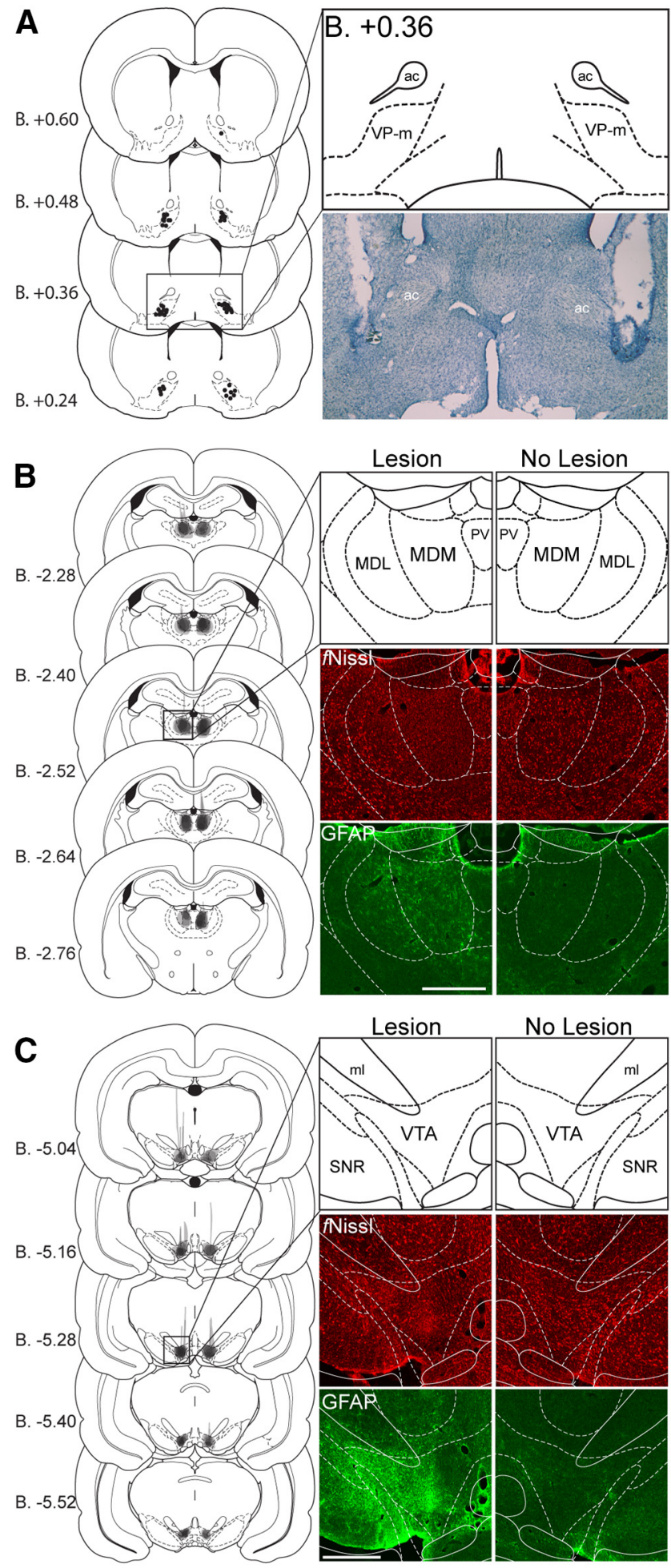

Figure 4. Experiment 2. A-C, Cannulae and lesion placements. Left, Schematic representation of cannulae placements in the VP-m or the extent of the lesion in the MD or the VTA of all animals included (Paxinos and Watson, 2007). Right; Photomicrographs of cannula placement in the VP-m revealed by cresyl violet staining or lesion placement in the MD or VTA revealed by immunohistological staining of fluorescent Nissl (fNissl) and GFAP compared with the nonlesioned hemisphere. ac, Anterior commissure; MDM, mediodorsal thalamus nucleus, medial part; MDL, mediodorsal thalamus nucleus, lateral part; $\mathrm{ml}$, medial lemniscus; PV, paraventricular thalamic nucleus; SNR, substantia nigra, reticula part; VTA, ventral tegmental area. Scale bar, $500 \mu \mathrm{m}$. lever press performance at what appears to be a similar rate during this period. ANOVA conducted on factors of Group and Minute found an effect of Group $\left(F_{(4,33)}=7.78, p<0.001\right)$, Minute $\left(F_{(7,231)}=41.68, p<0.001\right)$, and a Group by Minute interaction $\left(F_{(28,231)}=2.06, p=0.002\right)$. Assessment of the Group effect across this extinction period found differences in minutes $1-7$ (smallest $F_{(4,33)}=3.12, p=0.03$ ), but no difference in minute $8\left(F_{(4,33)}=1.86, p=0.14\right)$. However, responding in Group VTAc was clearly not, at least numerically, as fully extinguished and the lack of statistical difference may just reflect a floor effect.

Examination of Pre-CS responding throughout the specific PIT test supports this assessment (Fig. 5D). The higher level of responding in Group VTAc was found to persist throughout the session and Figure 5D shows that, although it reduced further in all other groups, the lever pressing per minute during the Pre-CS period across trials in Group VTAc remained high. ANOVA conducted on factors of Group and Trial (1-8) found an effect of $\operatorname{Group}\left(F_{(4,33)}=4.48, p=0.005\right), \operatorname{Trial}\left(F_{(4,33)}=7.88, p<0.001\right)$, and a Group by Trial interaction $\left(F_{(4,33)}=3.32, p<0.001\right)$. Further analysis of this interaction revealed an effect of Group on trials $1,3,5,6$, and 7 (smallest $F_{(4,33)}=3.02, p=0.03$ ), with responding in Group VTAc differing from the other groups on trials 3-8 (smallest $F_{(1,36)}=4.55, p=0.04$ ). Generally, these results suggest that performance in Group VTAc, whereas showing a specific PIT effect, was generally disinhibited and so less sensitive overall to extinction than performance in the other groups.

$c$-Fos expression in the MD and VTA after VP-m inactivation Levels of c-Fos expression in the MD and VTA were assessed to reveal any changes in circuit-related c-Fos expression induced by pharmacological inactivation of the VP-m (MDi, $n=5$; MDc, $n=5$; VTAi, $n=5$; VTAc, $n=6$ ). Three sections containing the $\mathrm{MD}$ or VTA were quantified in three regions per animal. Figure $6 A$ illustrates the respective regions that were quantified for each group. Because no differences were expected in similar regions across groups (e.g., c-Fos in the MD with an intact ipsilateral VP-m should not be predicted to differ between an animal in Group MDi, VTAi, or VTAc), quantifications of these regions were first compared with combined regions across groups for further analyses. In the ipsilateral hemisphere with an intact VP-m, ANOVAs revealed no differences in c-Fos expression between Groups MDi, MDc, and VTAc in the $\operatorname{MD}\left(F_{(2,13)}=1.24\right.$, $p=0.32$ ) nor differences between Groups MDi, MDc, and VTAi in the VTA in $\mathrm{TH}^{-}$neurons $\left(F_{(2,12)}=0.36, p=0.70\right)$ and $\mathrm{TH}^{+}$ neurons $\left(F_{(2,12)}=2.12, p=0.16\right)$. Similarly, in the hemisphere with an inactivated VP-m, there were no differences in c-Fos expression between Groups MDc, VTAi, and VTAc in the MD $\left(F_{(2,13)}=0.29, p=0.75\right)$ nor in the VTA between Groups MDi, MDc, and VTAc in both $\mathrm{TH}^{-}\left(F_{(2,13)}=0.01, p=0.99\right)$ and $\mathrm{TH}^{+}$ $\left(F_{(2,13)}=0.18, p=0.84\right)$ neurons.

Equivalent regions across groups were then collapsed and c-Fos expression in the MD and VTA with an intact VP-m was compared against the expression in the two regions when the VP-m was inactivated. Figure $6 B$ shows examples of c-Fos immunoreactivity in the MD and VTA with an intact or inactivated VP-m in the same hemisphere. It is clear from the images that both the MD and VTA regions show a marked increase in the levels of c-Fos expression, indicating a change in neuronal activation compared with when the VP-m is not inactivated. ANOVA conducted on c-Fos expression in the MD found a significant increase in c-Fos when the VP-m was inactivated $\left(F_{(1,30)}=4.20, p=0.049\right.$; Fig. $\left.6 C\right)$; this was also observed in the VTA after inactivation of the VP-m (Fig. 

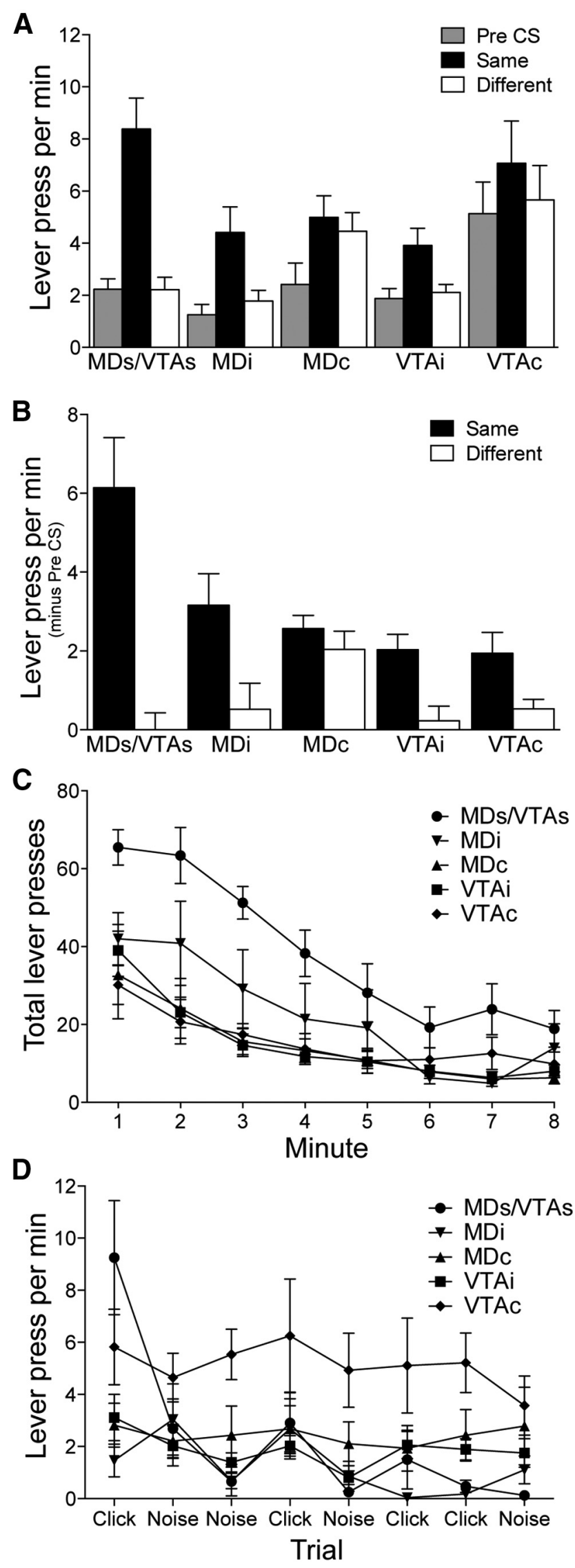

Figure 5. Experiment 2. Specific PIT test. $\boldsymbol{A}$, Lever press performance separated into responding during the Pre-CS period and seperately during the CS period, as responding on the lever associated with the same (Same) or different (Different) outcome as that predicted by the
$6 D)$, and there was significantly more c-Fos expression in both $\mathrm{TH}^{-}$ neurons $\left(F_{(1,29)}=24.59, p<0.001\right)$ and $\mathrm{TH}^{+}$neurons $\left(F_{(1,29)}=\right.$ 10.07, $p=0.004)$, although c-Fos levels on $\mathrm{TH}^{+}$neurons remained low regardless of VP-m manipulation.

\section{Discussion}

The neuronal and functional assessment of the direct thalamic and midbrain projections of the VP-m suggests that both are important for mediating different aspects of the effects of predictive cues on instrumental performance. Retrograde labeling in the VP-m produced by the two tracers is consistent with previous literature showing comparable numbers of neurons in the VP project to the MD and VTA and, in addition, a small population of neurons that send collaterals to both structures (Zahm, 2000; Tripathi et al., 2013). Examination of c-Fos found higher activity in VTA-projecting neurons in animals that underwent the specific PIT test compared with those only exposed to the CS, but not to those only exposed to the levers. There was, however, a selective increase in c-Fos during specific PIT compared with both control groups in MD-projecting neurons as well as in neurons innervating both structures. In contrast, only c-Fos expression in VTA-projecting neurons was found to correlate with the size of the specific PIT effect. It is also worth noting that, despite our previous detection of a significant increase in the levels of overall c-Fos activity in the VP-m during specific PIT (Leung and Balleine, 2013), the elevation observed in the current experiment failed to reach significance when compared with the two control groups, possibly due to differences in group sizes or the variability in specific PIT performance. Nevertheless, the correlation between overall c-Fos expression and net PIT performance suggests a relationship between the overall c-Fos expression in the VP-m and specific PIT.

The disconnection of the VP-m from the MD or VTA during specific PIT also produced differential effects behaviorally. Whereas control animals remained capable of demonstrating normal specific PIT, inactivation of the VP-m in the hemisphere contralateral to a lesion in the MD or VTA produced deficits that varied from typical performance. Disconnection of the MD from the VP-m produced an increase in responding during the CS presentations on both levers indiscriminately and the rats did not show any sensitivity to the response biasing effects of the specific predictive information provided by the CS. This pattern of results is reminiscent of that seen after bilateral MD lesions (Ostlund and Balleine, 2008) and suggests that the removal of the inhibitory input from the VP-m to the MD eliminates the ability of animals to use specific CS-outcome predictions to bias choice.

Conversely, whereas VP-m/VTA disconnection preserved specific PIT, the performance of animals receiving this disconnection was significantly and generally disinhibited; that is, they responded significantly more on the levers during the Pre-CS period than the other groups. This pattern of responding was sustained throughout the entire specific PIT test and, although it

$\leftarrow$

$\mathrm{CS}$, for animals that received a saline infusion into the VP-m (MDs/VTAs; MDs, $n=4$; VTAs, $n=$ 4) or an infusion of muscimol into the VP-m in the ipsilateral hemisphere (MDi, $n=7$ and VTAi, $n=9$ ) or in the contraltateral hemisphere to the lesion (MDc, $n=7$ and VTAc, $n=7$ ). $\boldsymbol{B}$, Lever press performance during $C S$ presentations minus responding during Pre-CS periods on the lever associated with the same (Same) and different (Different) outcome as predicted by the CS. C, Rate of extinction of lever pressing on the two levers before any presentations of the CS revealed that all groups were responding at a similar level by the last minute. $\boldsymbol{D}$, Lever press per minute during the Pre-CS periods across trials in the specific PIT test found that high levels of Pre-CS responding were sustained throughout the test in Group VTAC. 
was clear that this group could extinguish responding, they appeared less sensitive to this manipulation, particularly after CS presentations. This raises the possibility that, for these animals, the excitatory effects of the CS on responding extended into periods after the CS presentation. Alternatively, control animals may be using both the presence and absence of a CS to initiate and refrain from responding, respectively. From this perspective, animals without the VP-m/VTA connection may lack the ability to inhibit responding when the CS is no longer present.

Whereas VP-m-VTA disconnection appeared to disinhibit performance during specific PIT, bilateral inactivation of the VTA on test has been reported to generally inhibit performance (Corbit et al., 2007). Importantly, what is consistent across the two manipulations is that animals retain their ability to use specific stimulusoutcome predictions to bias choice. Aside from the well described GABAergic input from the VP to the VTA targeting both DA and non-DA neurons (Geisler and Zahm, 2005; Mahler and Aston-Jones, 2012; Watabe-Uchida et al., 2012; Hjelmstad et al., 2013), there have also been reports of glutamatergic neurons in the VP, particularly in the rostral region, which project to the VTA (Hur and Zaborszky, 2005; Geisler et al., 2007). Given the variety of inputs, disinhibition of the VTA after VP-m inhibition may not be that surprising. Disinhibition of the VTA with $\mathrm{GABA}_{\mathrm{A}}$ receptor antagonists have been shown to increase locomotor activity (Mogenson et al., 1979) and induce conditioned place preference (Laviolette and van der Kooy, 2001). In a recent study, Mahler et al. (2014) assessed the role of the input from the rostral VP onto VTA DA neurons in cue-induced reinstatement of cocaine seeking, a paradigm assessing the motivational influence of Pavlovian cues on action vigor. They found that, when VTA neurons were disinhibited locally using a $\mathrm{GABA}_{\mathrm{A}}$ antagonist, cue reinstatement was enhanced in similar fashion to our observation of increased lever pressing after VTA disinhibition induced by VP-m inactivation.

Finally, both the MD and VTA showed an elevation in c-Fos levels after VP-m inactivation. The increase in c-Fos in both regions may reflect trans-synaptic changes due to VP-m inactivation, implying that both connections with the VP-m are needed for normal specific PIT performance; whereas animals with two intact connections in the same hemisphere (i.e., in Groups MDi and VTAi) perform normally, those with disruption to either connection bilaterally (i.e., Groups MDc and VTAc) do not. Although c-Fos expression in VTA-projecting neurons revealed no selective difference in activation compared with controls, this activation was correlated with the size of the specific PIT effect. Because the disruption of this connection preserves the ability to show specific PIT but elevates overall responding, this connec-
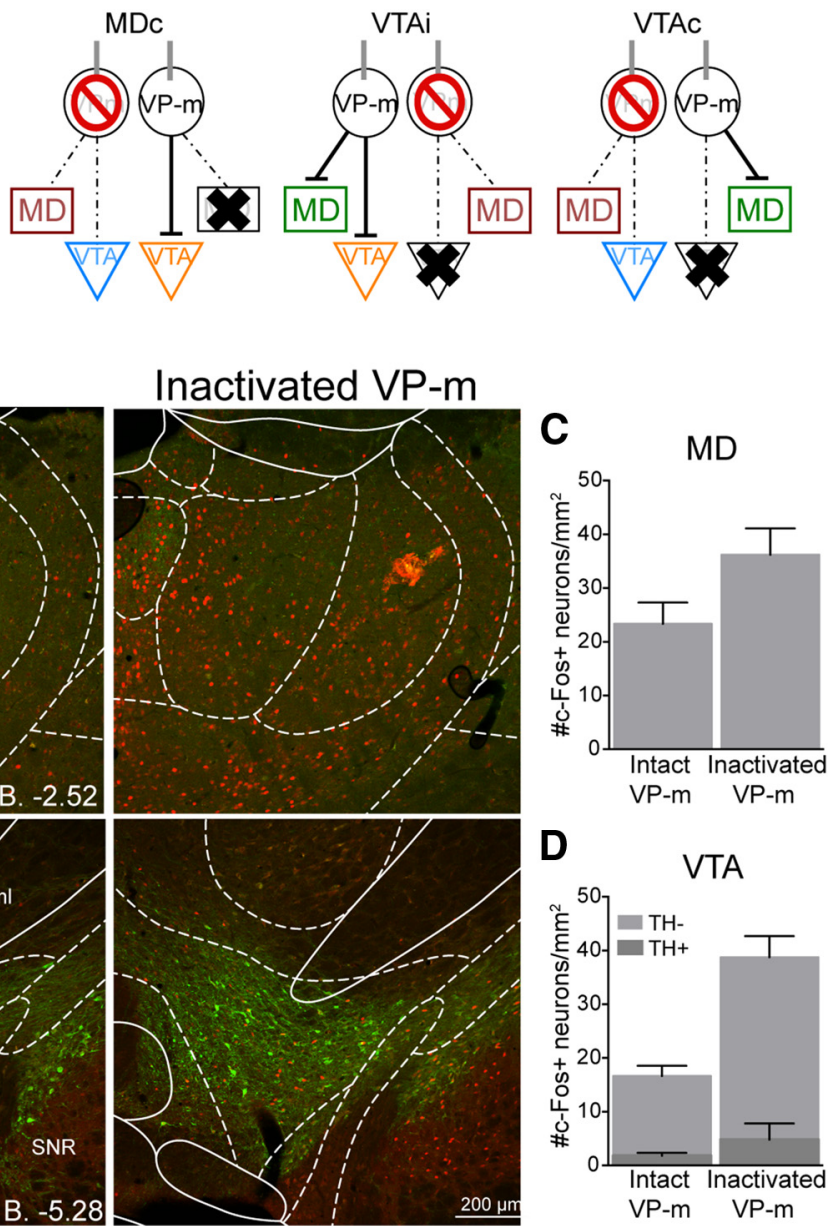

Figure 6. Experiment 2. c-Fos expression in the MD and VTA after VP-m inactivation. $\boldsymbol{A}$, Three regions in each animal were collapsed for analysis. $\boldsymbol{B}$, Photomicrographs of $c-$ Fos expression in the MD and VTA after an infusion of muscimol into the VP-m (right) compared with no manipulation of the VP-m (left). C, D, Quantification of c-Fos expression in the MD with an intact . Neurons in the VTA were further separated as those that were $\mathrm{TH}^{+}$or $\mathrm{TH}^{-}$. Similarly, c-Fos expression in both types was elevated in the VTA with an intactivated ipsilateral VP-m $(n=16)$ compared with an intact ipsialteral VP-m $(n=$ 15). MDM, Mediodorsal thalamus nucleus, medial part; MDL, mediodorsal thalamus nucleus, lateral part; $m$ l, medial lemniscus; $P V$, paraventricular thalamic nucleus; SNR, substantia nigra pars reticula part.

tion appears to generally inhibit inappropriate actions during the specific PIT test, thereby improving the effect size. Conversely, c-Fos expression in MD-projecting neurons, as well as those projecting to both the MD and VTA, was higher than both control groups but was not correlated to the size of specific PIT, implying that the VP-m/MD connection may not control how much the animal responds, only the bias in responding that the animal shows toward the congruent response.

\section{Specific subcircuit mediating the response biasing effects of predictive stimuli}

When combined with our previous observations (Leung and Balleine, 2013), the current results suggest that neurons in the VP-m that receive input from the NAc-S are normally activated during specific PIT and, in turn, act to inhibit both the MD and VTA. The suggestion that the former pathway mediates the response bias in choice performance during specific PIT whereas the latter pathway mediates the relative size of that bias agrees generally with current views of distinct functions of direct and indirect pathways through the basal ganglia. Although the traditional view of basal ganglia circuitry suggests that activation of the direct 
pathway tends to promote action and activation of the indirect pathway suppresses action, there have also been reports of cooperation between the two pathways during coordinated action, where activation of the direct pathway promotes a specific action and activation of the indirect pathway promotes the suppression of competing actions (Mink, 1996; Brown, 2007; Kravitz et al., 2012; Cui et al., 2013). Nevertheless, specific hypotheses as to whether the deficits observed here reflect one or other process are complicated by the fact that the projection from the NAc-S to the VP-m contains neurons belonging to both a direct and indirect pathway (Lu et al., 1998; Zhou et al., 2003).

The specific PIT effect has, however, been found to rely on the activation of medium spiny neurons (MSNs) in the NAc-S expressing D1 receptors and not those expressing D2 receptors (Laurent et al., 2015). It is likely, therefore, that the NAc-S to VP-m pathway important for specific PIT is driven by the D1MSN projections to the VP-m. Intriguingly, as D1-MSNs in the NAc-S are innervating MD-projecting VP-m neurons, they may be thought to satisfy definitions of direct pathway neurons; that is, as MSNs that project to basal ganglia output nuclei that innervate nonbasal ganglia structures (Gerfen and Surmeier, 2011) that function to facilitate responding on the appropriate lever during specific PIT. Indeed, disconnection of the NAc-S and VP-m has effects that are remarkably similar to those induced by disconnection of the VP-m and MD consistent with a serial pathway; both manipulations result in a general increase in responding on the levers over baseline during presentations of the CS but without any bias between them. Similarly, MSNs in the NAc-S innervating VTA-projecting VP-m neurons could reflect an indirect pathway- using a multisynaptic circuit to reach the output nuclei of the basal ganglia-responsible for the general inhibition of competing or inappropriate actions (Gerfen and Surmeier, 2011). There is, in addition, a population of neurons that express both D1 and D2 receptors that is larger in the NAc-S than other regions of the striatum (Bertran-Gonzalez et al., 2008). These neurons not only display both a GABA and glutamate phenotype (Perreault et al., 2012), but also express a D1-D2 receptor heteromer that appears to have distinct pharmacology and cell signaling properties (Lee et al., 2004; Rashid et al., 2007; Verma et al., 2010). Whether these cells and their respective projection targets play a distinct role is currently unknown and experiments investigating the degree of segregation in their functional connections will be of interest.

\section{References}

Bertran-Gonzalez J, Bosch C, Maroteaux M, Matamales M, Hervé D, Valjent E, Girault JA (2008) Opposing patterns of signaling activation in dopamine D1 and D2 receptor-expressing striatal neurons in response to cocaine and haloperidol. J Neurosci 28:5671-5685. CrossRef Medline

Brown P (2007) Abnormal oscillatory synchronisation in the motor system leads to impaired movement. Curr Opin Neurobiol 17:656-664. CrossRef Medline

Colwill RM, Rescorla RA (1988) Associations between the discriminative stimulus and the reinforcer in instrumental learning. J Exp Psychol 14: $155-164$.

Corbit LH, Muir JL, Balleine BW (2003) Lesions of mediodorsal thalamus and anterior thalamic nuclei produce dissociable effects on instrumental conditioning in rats. Eur J Neurosci 18:1286-1294. CrossRef Medline

Corbit LH, Janak PH, Balleine BW (2007) General and outcome-specific forms of Pavlovian-instrumental transfer: the effect of shifts in motivational state and inactivation of the ventral tegmental area. Eur J Neurosci 26:3141-3149. CrossRef Medline

Corbit LH, Balleine BW (2011) The general and outcome-specific forms of Pavlovian-instrumental transfer are differentially mediated by the nucleus accumbens core and shell. J Neurosci 31:11786-11794. CrossRef Medline

Cui G, Jun SB, Jin X, Pham MD, Vogel SS, Lovinger DM, Costa RM (2013)
Concurrent activation of striatal direct and indirect pathways during action initiation. Nature $494238-242$.

Dickinson A, Balleine BW (2002) The role of learning in the operation of motivational systems. In: Steven's handbook of experimental psychology: learning, motivation and emotion, Vol 3 (Gallistel C, ed), pp 497-534. New York: Wiley.

Geisler S, Zahm DS (2005) Afferents of the ventral tegmental area in the rat-anatomical substratum for integrative functions. J Comp Neurol 490: 270-294. CrossRef Medline

Geisler S, Derst C, Veh RW, Zahm DS (2007) Glutamatergic afferents of the ventral tegmental area in the rat. J Neurosci 27:5730-5743. CrossRef Medline

Geisler S, Marinelli M, Degarmo B, Becker ML, Freiman AJ, Beales M, Meredith GE, Zahm DS (2008) Prominent activation of brainstem and pallidal afferents of the ventral tegmental area by cocaine. Neuropsychopharmacology 33:2688-2700. CrossRef Medline

Gerfen CR, Surmeier DJ (2011) Modulation of striatal projection systems by dopamine. Annu Rev Neurosci 34:441-466. CrossRef Medline

Heimer L, Zahm DS, Churchill L, Kalivas PW, Wohltmann C (1991) Specificity in the projection patterns of acumbal core and shell in the rat. Neuroscience 41:89-125. CrossRef Medline

Hjelmstad GO, Xia Y, Margolis EB, Fields HL (2013) Opioid modulation of ventral pallidal afferents to ventral tegmental area neurons. J Neurosci 33:6454-6459. CrossRef Medline

Hur EE, Zaborszky L (2005) Vglut2 afferents to the medial prefrontal and primary somatosensory cortices: a combined retrograde tracing in situ hybridization study. J Comp Neurol 483:351-373. CrossRef Medline

Kalivas PW, Churchill L, Romanides A (1999) Involvement of the pallidalthalamocortical circuit in adaptive behavior. Ann N Y Acad Sci 877:64-70. CrossRef Medline

Kravitz AV, Tye LD, Kreitzer AC (2012) Distinct roles for direct and indirect pathway striatal neurons in reinforcement. Nat Neurosci 15:816-818. CrossRef Medline

Laurent V, Leung B, Maidment N, Balleine BW (2012) Mu- and deltaopioid-related processes in the accumbens core and shell differentially mediate the influence of reward-guided and stimulus-guided decisions on choice. J Neurosci 32:1875-1883. CrossRef Medline

Laurent V, Bertran-Gonzalez J, Chieng BC, Balleine BW (2014) Delta-opioid and dopaminergic processes in accumbens shell modulate the cholinergic control of predictive learning and choice. J Neurosci 34:1358-1369. CrossRef Medline

Laurent V, Wong FL, Balleine BW (2015) $\delta$-opioid receptors in the accumbens shell mediate the influence of both excitatory and inhibitory predictions on choice. Br J Pharmacol 172:562-570. Medline

Laviolette SR, van der Kooy D (2001) GABA A receptors in the ventral tegmental area control bidirectional reward signalling between dopaminergic and non-dopaminergic neural motivational systems. Eur J Neurosci 13:1009-1015. CrossRef Medline

Lee SP, So CH, Rashid AJ, Varghese G, Cheng R, Lança AJ, O'Dowd BF, George SR (2004) Dopamine D1 and D2 receptor Co-activation generates a novel phospholipase C-mediated calcium signal. J Biol Chem 279: 35671-35678. CrossRef Medline

Leung BK, Balleine BW (2013) The ventral striato-pallidal pathway mediates the effect of predictive learning on choice between goal-directed actions. J Neurosci 33:13848-13860. CrossRef Medline

Lu XY, Ghasemzadeh MB, Kalivas PW (1998) Expression of D1 receptor, D2 receptor, substance $\mathrm{P}$ and enkephalin messenger RNAs in the neurons projecting from the nucleus accumbens. Neuroscience 82:767-780. Medline

Mahler SV, Aston-Jones GS (2012) Fos activation of selective afferents to ventral tegmental area during cue-induced reinstatement of cocaine seeking in rats. J Neurosci 32:13309-13026. CrossRef Medline

Mahler SV, Vazey EM, Beckley JT, Keistler CR, McGlinchey EM, Kaufling J, Wilson SP, Deisseroth K, Woodward JJ, Aston-Jones G (2014) Designer receptors show role for ventral pallidum input to ventral tegmental area in cocaine seeking. Nat Neurosci 17:577-585. CrossRef Medline

McAlonan GM, Robbins TW, Everitt BJ (1993) Effects of medial dorsal thalamic and ventral pallidal lesions on the acquisition of a conditioned place preference: further evidence for the involvement of the ventral striatopallidal system in reward-related processes. Neuroscience 52:605-620. CrossRef Medline

Mink JW (1996) The basal ganglia: focused selection and inhibition of competing motor programs. Prog Neurobiol 50:381-425. CrossRef Medline

Mogenson GJ, Wu M, Machanda SK (1979) Locomotor activity initiated by 
microinfusions of picrotoxin into the ventral tegmental area. Brain Res 161:311-319. CrossRef Medline

Ostlund SB, Balleine BW (2008) Differential involvement of the basolateral amygdala and mediodorsal thalamus in instrumental action selection. J Neurosci 28:4398-4405. CrossRef Medline

Parnaudeau S, Taylor K, Bolkan SS, Ward RD, Balsam PD, Kellendonk C (2015) Mediodorsal thalamus hypofunction impairs flexible goaldirected behavior. Biol Psychiatry 77:445-453. Medline

Paxinos G, Watson C (2007) The rat brain in stereotaxic coordinates, Ed 6. San Diego: Academic.

Perreault ML, Fan T, Alijaniaram M, O'Dowd BF, George SR (2012) Dopamine D1-D2 receptor heteromer in dual phenotype GABA/glutamatecoexpressing striatal medium spiny neurons: regulation of BDNF, GAD67 and VGLUT1/2. PLoS One 7:e33348. CrossRef Medline

Rashid AJ, So CH, Kong MM, Furtak T, El-Ghundi M, Cheng R, O'Dowd BF, George SR (2007) D1-D2 dopamine receptor heterooligomers with unique pharmacology are coupled to rapid activation of $\mathrm{Gq} / 11$ in the striatum. Proc Natl Acad Sci U S A 104:654-659. CrossRef Medline

Smith RJ, Lobo MK, Spencer S, Kalivas PW (2013) Cocaine-induced adaptations in D1 and D2 accumbens projection neurons (a dichotomy not necessarily synonymous with direct and indirect pathways). Curr Opin Neurobiol 23:546-552. CrossRef Medline

Tripathi A, Prensa L, Mengual E (2013) Axonal branching patterns of ventral pallidal neurons in the rat. Brain Struct Funct 218:1133-1157. Medline

Verma V, Hasbi A, O’Dowd BF, George SR (2010) Dopamine D1-D2 receptor heteromer-mediated calcium release is desensitized by D1 receptor occupancy with or without signal activation: dual functional regulation by G protein-coupled receptor kinase 2. J Biol Chem 285:35092-35103. CrossRef Medline

Watabe-Uchida M, Zhu L, Ogawa SK, Vamanrao A, Uchida N (2012) Whole-brain mapping of direct inputs to midbrain dopamine neurons. Neuron 74:858-873. CrossRef Medline

Zahm DS (2000) An integrative neuroanatomical perspective on some subcortical substrates of adaptive responding with emphasis on the nucleus accumbens. Neurosci Biobehav Rev 24:85-105. CrossRef Medline

Zahm DS, Heimer L (1990) Two transpallidal pathways originating in the rat nucleus accumbens. J Comp Neurol 302 437-446.

Zhou L, Furuta T, Kaneko T (2003) Chemical organization of projection neurons in the rat accumbens nucleus and olfactory tubercle. Neuroscience 120:783-798. CrossRef Medline 